\title{
The Silence of Female Sexual Offending: A Public Health Issue
}

\author{
Drs. James F. Anderson ${ }^{1}$, Kelley Reinsmith-Jones ${ }^{2}$, Tazinski Lee ${ }^{3}$, Willie M. Brooks, Jr. ${ }^{4}$ \\ ${ }^{1}$ Thomas Harriot College of Arts \& Sciences, Professor of Criminal Justice, East Carolina University, Greenville, NC, \\ USA. \\ ${ }^{2}$ College of Health and Human Performance, Assistant Professor of Social Work, East Carolina University, Greenville, \\ NC, USA. \\ ${ }^{3}$ College of Professional Studies, Associate Professor of Criminal Justice, Grambling State University, Grambling, LA, \\ USA. \\ ${ }^{4}$ College of Liberal Arts \& Social Sciences, Assistant Professor of Criminal Justice, Savannah State University, Savannah, \\ GA, USA.
}

Correspondence: James F. Anderson, Professor, Department of Criminal Justice, East Carolina University, Greenville, NC, USA.

Received: January 7, 2021

doi:10.11114/ijsss.v9i2.5153
Accepted: January 28, $2021 \quad$ Available online: February 8, 2021

URL: https://doi.org/10.11114/ijsss.v9i2.5153

\begin{abstract}
The idea that females can engage in sexually predatory behavior against children and adolescence is difficult to convey to the lay pubic since most of society believes the notion defies conventional ways of viewing the gendered nature and roles that women traditionally perform. Despite this, scholars and researchers examining child sexual abuse are beginning to report on silent offenders (women and young females) and their victimizations that have been largely ignored by criminal justice personnel who are responsible for holding sex offenders accountable. We argue that female sex offending is more common than believed and is both a criminal justice and a public health issue. We also argue that until society recognizes that sex offending is not a gendered crime, more cases will escape the attention of both criminal justice and public health systems that are in positions to punish and treat where appropriate.
\end{abstract}

Keywords: female sexual offender, sexual abuse, epidemiology, public health approach

\section{Introduction}

Research on female sexual offenders (FSO) is limited at best. In fact, critics often argue that there is little systematic and representative research on the FSO. FSOs, like other female offenders, tend to be viewed by most in society as, "out of sight; therefore, out of mind." This view exists largely because crime has always been predominately and disproportionately committed by men (Beirne \& Messerschmidt, 2011). Moreover, studies reveal that many experts who either investigate or treat the perpetrators or victims of sexual abuse (such as law enforcement officers and psychologists) also report that it is more likely than not, that men, will engage in sex offending (Landor \& Eisenchlas, 2012). On the other hand, females have traditionally been regarded as nurturing and caring, and if by chance they commit a sexual offense, there has always been some underlying cause as to why. Recently, there have been cases involving inappropriate sexual behavior between female teachers and male students, as well as female babysitters. However, such cases do not completely examine the vast sexual crimes committed by females or the complexity in the roles that they play in these cases.

Some studies reveal that FSOs represent a small percentage of all sex offenders in the United States. For example, McLeod \& Craft (2015) reported that 20\% of sexual offences involved females and between 15 to $20 \%$ of all sexual offenses were perpetrated by females, yet only $1 \%$ of sex offenders who were in prison at the time of the study were females. Moreover, a study by Stemple, Flores, \& Meyer (2017) examined female sexual crimes in the US by analyzing data from the Centers for Disease Control and Prevention (CDC) and the Bureau of Justice Statistics (BJS) from 2008 through 2013. These data revealed that a female perpetrator forced the sexual act in $79.2 \%$ of the cases. Furthermore, Stemple and colleagues examined U.S. Census Bureau data in 2012 and revealed that in a study that examined the percentage of women and men who admitted to forcing sex on someone, $43.6 \%$ of the subset were women, compared with $56.4 \%$ of men, respectively. This finding reveals the presence of women's involvement in sexual crimes may not be as uncommon or the anomaly that many people think. To a majority of society, the idea that women would engage in 
sexual offending defies belief and suggests something more sinister, or even taboo since it challenges conventional perceptions and stereotypes about the role and socialization of women as caring, nurturing, and protecting children (Zack, Long, \& Dirk, 2018). Despite this, the idea that women can be just as culpable in sexually predatory behavior as men is an idea that is gaining momentum as scholars report that FSOs are more common than previously thought (Stemple et al., 2017; Cortoni, Babchishin, \& Rat, 2017; Jarrett, 2017). This finding is not only evident in the U.S., but it is also being discovered in cross cultural studies in countries such as: England, Germany, Canada, and Australia (Tozdan, Briken, \& Dekker, 2019). Because scant attention has been given to FSOs, our investigation examines this neglected area of public health research. Therefore, this paper is divided into four parts. Part One explores the prevalence and typologies of FSOs. Part Two provides theoretical understandings of FSOs. Part Three addresses female sex offending as a public health issue. In Part Four, we offer policy implications that can help reduce female sexual offending.

\section{Prevalence and Typologies of FSOs}

While sexual abuse statistics show that children and adolescence are targeted by both men and women perpetrators, Levine (2011) reported that each year in the US, an estimated 1.5 million girls, and 1.1 million boys are the victims of female sexual abuse. In fact, the evidence suggests that nationally when it comes to sexual crimes, men and women commit them at 96\%, and up to 5\%, respectively (Cortoni, Hanson, \& Coache, 2010). This is an increase for females from a previous $1 \%$ (Greenfield, 1997). However, even higher rates have been reported. For example, Green (1999) reported FSO victimization in between 6\%-24\% of survey respondents, while Bumby \& Bumby (1997) reported rates of FSO victimization between $2 \%-78 \%$ in their study. But, when the victims of sexual abuse are children, the numbers for males and females appear very similar. Notwithstanding, these perpetrators may use different approaches to sexually abuse children. Some research finds that women tend to sexually abuse children (primarily young boys) who are family members within the context of their caregiver role. Despite this, some experts are not so sure contending that FSOs have different modus operandi. For example, a study by Kaufman and colleagues (1995), reported that $88 \%$ of FSOs were teachers and 23\% were babysitters. Other research revealed that FSOs are overwhelmingly babysitters, teachers, and caregivers (Burgess-Proctor et al., 2017). Comartin and colleagues (2018) reported that unlike men, women sexual offenders are more likely to abuse child victims, be the parent of the victim, have a co-offender, and repeatedly target the same victim overtime (Williams \& Bierie, 2014; McLeod, 2015). In fact, Bunting (2006) found that children sexually abused by their mothers reported significantly more psychological and emotional damage than those assaulted by male perpetrators.

A disturbing report on women sexual offenders was revealed in a justice department investigation. According to a $U S$ Department of Justice study that contained 60,991 sexual assault victims, female offenders were more likely to sexually assault victims under the age of 6 years old (Bunting, 2006). The study reported that among the very young that were sexually victimized, $12 \%$ of the predators were females. For those victims aged 6-12, 6\% of the offenders were females. For victims who were between ages of 12-17,3\% of the offenders were females (Snyder, 2000; Bourke et al., 2014). Additionally, statistics show that female offenders comprised less than $10 \%$ of those arrested for committing sexual crime. More specifically, these data suggest that women represent only $1 \%$ of all adult arrests for forcible acts of rape, and 6\% of all adult arrests for other sex crime. Similarly, Sandler \& Freeman (2007) reported that while the arrest rates for female involvement in sex crimes is nationally consistent, their conviction rates range between $1 \%$ and $6 \%$ throughout the US, but vary from jurisdiction to jurisdiction. In the United Kingdom, for 2011, $1.8 \%$ of prosecuted sex offenses were committed by women (Home Office, 2013). Research also reveals that when it comes to the age of FSOs, juvenile arrests data finds that adolescent female offenders account for 3\% of forcible rape cases, and $5 \%$ of other violent sex offenses (Snyder \& Sickmund, 2006). Other studies, such as Finkelhor, Ormrod, \& Chaffin (2009) revealed that teen females account for $7 \%$ of juvenile sex offenders. They contend that young female offenders are more likely than their male counterparts to have more victims and episodes of abuse with their own young relatives. Some reports find that while many FSOs are in their 20s and 30s, they are typically younger when they start sexually abusing children (Bourke et al., 2014; Johansson-Love \& Fremouw, 2009). Finkelhor (2008) found that typically young sex offenders begin victimizing others at age 12 and then the process slows or levels off at age fourteen. However, in some cases, offenders have been younger than twelve.

Because of methodological weaknesses that include the use of convenience samples and case studies in FSO research, it is impossible for researchers to generalize and infer from many investigations (Saradjian, 2010; Tozdan et al., 2019; Travin, Cullen, \& Potter, 1990). This is only one factor that prevents experts and scholars from assessing the total number of incidents and cases that occur each year. In studies of FSOs, researchers rely on surveys, official data, and qualitative analyses (all of which present concerns regarding accuracy) in research. Nevertheless, researching FSOs is also challenging (since scant research exists) and made more complicated by the fact that child sexual abuse, whether perpetrated by male or female, is often committed in private. Therefore, the actual number of incidents are likely to go 
unreported since, in most cases, research finds that sex crimes are only seen by the victims and perpetrators (Wiseman, 2015). With sibling sexual abuse, cases appear to go unreported because therapists and parents have most often referred to the behavior as experimentation and not abuse (Rowntree, 2007). It is also believed that sexual behavior among siblings is considered taboo. Thus, researchers are discouraged from investigating such matters (Tidefors, Arvidsson, Ingevaldson \& Larsson (2010). Another reason for under-reporting may be that FSO crimes have been viewed as a product of mental illness and not criminal intent. Research reveals that high rates (30-59\%) of psychological disorders have been reported in samples of FSOs (Faller, 1995; Lewis \& Stanley, 2000; O'Connor, 1987; Wijkman, Bijleveld, \& Hendriks, 2010). Moreover, sex crimes committed by females against older males are rarely reported since males are reluctant to contact the authorities feeling ashamed and often viewing themselves as either unmasculine or that they will not be believed (Davies \& Rogers, 2006; Wijkman et al., 2010). For example, Wiseman (2015) reported that older male victims have been blamed for initiating the abuse, making it even more difficult for male victims to defend themselves. Researchers and scholars believe it is vitally important that statistics and data are collected in order to know the true nature, extent, and scope of child sexual abuse committed by FSOs so that community residents, practitioners, and policy-makers are keenly aware of effective prevention and treatment models (Wiseman, 2015).

Despite these concerns, there are efforts made to assess the number of female sexual offenses that occur. For example, Tozdan, Briken, \& Dekker (2019) reported that in the U.S., official crime data from the National Incident Based Reporting System (NIBRS), that focused on female sexual offenses committed by relatives of the victims, revealed that from 1991-1996, women offenders committed an estimated 40, 804 sexual crimes against children and adolescents between the ages 1 through 17 . More specifically, NIBRS data revealed that 8,539 victims were younger than $6 ; 12$, 260 victims were age 6-12; and 20, 005 victims were between the ages of 12-17. Moreover, the type of sexual offences ranged from "vaginal and anal penetration or attempted penetration with fingers, penis, objects, or oral sex, attempted oral sex, unwanted sexual touching or fondling" (Tozdan et al., 2019, p2). Similarly, Williams \& Bierie (2014) examined NIBRS data, but focused on 1991 through 2011 as their timeframe. They reported that 5\% of more than 800, 000 incidents of sexual offenses involved FSOs. However, unlike Tozdan and colleagues' analysis, William \& Bierie reported that $61.9 \%$ of the cases $(n=26,630)$ were women acting alone, and they were co-offenders in the remaining $38.1 \%(\mathrm{n}=16,388)$ of incidents. In these cases, the majority involved a male co-offender $(\mathrm{n}=13,986)$. This finding clearly establishes that in two thirds of female sexual offending cases, they primarily engage in this behavior on their own.

Although sexual offenses committed by women appear shocking, child abuse experts warn that they may not even come close to approaching the actual number of sexual incidents that children and adolescents experience each year since this crime is similar to other forms of assaultive violence -- they typically go unreported and or underreported. As such, if these incidents are not reported to police, they are not included in the UCR or NIBRS. For example, research surveys reveal that the numbers of FSOs are higher, but so is the number of victims. For example, in 1996, the National Incidence Study by the National Centers on Child Abuse and Neglect reported that 300,200 children were sexually abused by women (Boroughs, 2004). However, McLeod \& Craft (2015) provide that while examining the prevalence of FSOs based on victimization surveys, they discovered that the National Abuse and Neglect Data System (NCAND) showed that from 2009-2010, there were an estimated 66,765 FSO victims.

\subsection{Typologies of Adult and Adolescent FSOs}

FSOs are not a monolithic group that engage in the same sexual behavior, target the same victims for the same reasons, but rather, they and their behaviors are more complex since they have different experiences and use various modus operandi's. In fact, research shows that this special population of sex offenders is composed of adults and adolescence who are diverse since they are influenced by different motives to commit sex offenses (Davin et al., 1999; Matthews et al., 1997). Because of this, researchers, justice officials, and health experts who study, punish and treat them should recognize there are several typologies of FSOs. This may suggest that they have a different set of needs which implies that they must be treated differently. Nevertheless, the literature reveals that FSOs are adults as well as adolescents (Applewhite, 2005).

\subsection{Adult Female Sexual Offenders (FSOs)}

Generally speaking, there are three types of adult FSOs: predisposed intergenerational; teacher/lover; and male coerced. However, Syed \& Williams (1996) added an additional typology: the angry, impulsive offender who appears to act on her own, alone, and in an angry and impulsive manner toward male adult victims. First, female offenders who are predisposed have a history of sex abuse as a child. They have typically been victims of incest by family members and caretakers (Applewhite, 2005). Moreover, Barnes and colleagues (2009) revealed that these women are also likely to experience continual sexual victimization as adults. Some research (Mathews et al., 1989) reveals that they are likely to sexually abuse their own children and other young children who are also family members. When this occurs, they may 
become physical or sadistic with children while acting out sexual fantasies. Some studies report that many of these FSOs suffer from dissociative disorders and have been known to engage in bizarre and violent sexual behavior with children as young as six years old (Maniglio, 2011; Bartels \& Gannon, 2011). Because of the extent of their health problems, they are more difficult to treat compared with other FSOs. Second, the teacher/lover FSO forms relationship with students and view them as peers rather than minor children. After targeting and befriending them, they become the object of their desire. Vandiver \& Kercher (2004) refer to them as heterosexual nurturers. Research shows that teachers who target students report that they struggle with meeting and connecting with people their own age. These FSOs fail to understand that their relationship is criminally prohibited and punishable by law since they believe that they and the child are consenting participants (Hunter \& Matthews, 1997). Third, male coerced FSOs have histories of physically and sexually abusive relationships and they also suffer from substance abuse problems. They often display timid behavior while being controlled by an abusive male counterpart who forces them to engage in sexual behavior with their own children or other children such as relatives (Gannon \& Rose, 2008). Some research suggests that because they fear a violent coercive companion, they help him to live out his sexual fantasies. For example, they engage in sex with the male and child fearing physical threats and punishment. Other times, they may be motivated by hopelessness and powerlessness in the relationship. Research also reveals that even when coercive men leave relationships with FSOs, some of the women continue sexually abusing children (Gannon \& Rose, 2008).

\subsection{Adolescent Female Sexual Offenders (FSOs)}

Where adolescence is concerned, there are also three types of FSOs: sexually curious; sexually reactive; and repetitive abusers. First, sexually curious offenders overwhelmingly target those they have access to such as younger male children that they babysit. These FSOs do not appear to suffer from emotional or psychological harm. In fact, most studies indicate that they are sexually curious offenders who lack experience in sexual matters. Therefore, they use children as a resource for experimentation and to learn sexual behavior (Applewhite, 2005). Second, sexually reactive offenders have been sexually abused. Some research suggests that females who are exposed to early sexual trauma may experience hyper-sexuality or sexual problems that could manifest into them victimizing others. Moreover, studies show that adolescents who suffer extreme neglect may react in a sexual way to receive self-stimulation to relieve stress (Cohu, 2017). Researchers emphasize that not every child who experiences sexual abuse will become sexually aggressive. Experts who study sexually reactive adolescent offenders report that they recreate their own sexual victimization when they engage in sexual behavior. While most of these FSOs are emotionally disturbed, it is not severe enough to render them antisocial or dysfunctional in every case (Cohu, 2017). Third, repetitive abuser FSOs have family histories characterized as chaotic and sexually abusive. After early experiences with physical and sexual abuse, they suffer trauma, emotional disturbances, mental health problems, and even instability (Harris, 2010). To that end, healthcare experts warn that if these FSOs are not properly treated, they may become adult predisposed sexual offenders. Research reveals that these FSOs typically engage in repetitive, extensive, and severe abuse to many victims. Of the adolescent female offenders, this group is the most difficult to treat. As this section suggests, FSOs are not a monolithic group, but instead, they are diverse and motivated by various reasons. Thus, typologies are important in helping to assist justice officials, counselors, and clinicians in processing and treating adult and adolescent FSOs (Harris, 2010).

\section{Theoretical Understandings of FSOs}

A review of the criminal justice and criminological literature reveals that in the past, very little attention was devoted to FSOs, while researchers such as sociologists, psychologists, psychiatrists, and practitioners conducted the lion share of studies on this special population of sexual offenders. However, despite their best efforts, their research lacked analysis on the etiology of female sex offending. Some experts warn that without a theoretical explanation that is specific to women, it would be difficult to fully understand the motivation behind FSOs since most theories regarding sex offending have been based on male sex offenders. Therefore, FSOs have been understood from the prospective of their male counterparts. As such, FSOs have been treated as the generalized others when experts have tried to explain their sex offenses (Stathopoulos, 2014). Similarly, Harris (2010) and White \& Hines (2008) argue that female sex crimes cannot be explained or properly understood using male theories of crime. In an effort to address the behavior of female offenders, feminist scholars argue that the experiences women have are different compared with their male counterparts (Messerschmidts, 1997). As such, the crimes they commit should be researched using a gender-specific criminology that addresses the etiology of women's participation in crime (Chesney-Lind, 1995). While some efforts have been made to address FSOs, many scholars continue to use malestream theories to explain FSO.

\subsection{Radical Feminist Theory}

Harris (2010) and Hayes \& Baker (2014) argue that feminist criminology's use of pathways can help explain female sex offending. Radical feminist theory considers the powerlessness, exploitation, violence, and domination that females experience in patriarchal societies and how they routinely lead to the victimization of girls and women. It suggests that 
women are regulated to a subordinate status due to the structure of society and the positions men occupy. More specifically, radical feminists argue that in male dominated societies, men control all social institutions including the family. These scholars view the family as another oppressive institution controlled and socialized by men. Within the family, general roles and behaviors are structurally and culturally scripted so that women are reared to be subordinate and to accept their powerlessness as being sexual objects to men (Ollenburger \& Moore, 1992). Their lack of power is more intensified if females are sexually abused as children. Consequently, they may feel little control over their sexuality (Solomon, 1992). As a result, they may sexually abuse others as an expression of power. Therefore, "any abuse, neglect or over-discipline of children might be the only opportunity they have to feel in control" (Harris, 2010, $p$. 37). This does not suggests that FSOs use sexual victimizations as a resource to achieve masculinity since this is predatory behavior that reveals an exercise of dominance and power over victims, however, it does suggests their behavior is a form of oppositional femininity that departs from hegemonic femininity which is subordinate to hegemonic masculinity (Schippers, 2007). When females engage in sex offending, it is an opposite display of emphasized femininity (i.e., normal) or the stereotypical assigned cultural gender role and practice they are socialized to display such as being nurturing, caring towards children, and sexually passive. It is also a cultural breach of their script as the fairer sex which casts them as traitors to their gender (Linders \& van Gundy-Yoder, 2008). By engaging in sexual offenses, women challenge traditional gender roles by subscribing to a form of oppositional femininity (i.e., deviant) yet they are still doing gender, but they are doing gender differently (Hayes \& Baker, 2014; West \& Zimmerman, 1987). But what leads them to this brand of femininity?

\subsection{Developmental/Life-course Theory}

While its early efforts to explain FSOs were meager at best, criminological theories current use of developmental/life-course theory holds promise since it combines multifactorial explanations to understand gender related crimes (Beirne \& Messerschmidts, 2011). More specifically, developmental theory considers one's entire life-course beginning at childhood and progresses to later ages while closely examining different trajectories that one experiences. Trajectories are sequences of linked states within a defined set of behaviors or pathways over the life span (Benson, 2002; Elder, 1985). Some theorists argue that trajectories are the patterns of onset and desistance of behavior that occur overtime (Cale \& Lussier, 2011, p17). Researchers argue that the life-course approach uses biological, psychological, and social factors to examine the lived experiences of people to fully understand the different pathways that may explain their behavior (Benson, 1985). The life-course includes the impact of one's age and development, trajectories in various aspects of life that are interconnected, social and historical conditions influencing one's development, as well as efforts experienced to optimize one's development (Benson, 1985). Trajectories, especially antisocial ones include dimensions that have consequences for how people develop that include entrance, success, and timing (Thornberry, 1997). What is the trajectory of female sexual offenders? After experiencing sexual victimization, do they develop healthily or does the trajectory place them on a deviant or criminal pathway? What about the timing of their victimization? If the victimization occurs too early, perhaps while they are very young, does the trajectory where they find themselves, allow them time to transition from the victimization, or do they find themselves acting out or engaging in similar sexual victimizations?

Antisocial trajectories that people experience are often caused by individuals, family, and environmental factors that adversely affects them early in life (early-onset) and carry over into their adulthood. This could include experiencing sexual or physical abuse as a child and the effects of the victimization lingering throughout the life-course. According to Moffitt and colleagues (2002), a combination and excessive interaction between the individual, family, or environmental abuse, or risk factors over one's life course could increase a child's involvement in antisocial as well as criminal behavior; persistence in antisocial and criminal behavior; diversification of antisocial and criminal behavior, and serious violent offending. The research often suggests that it is because of these early negative experiences that some people are placed on a trajectory that may explain their future behavior. In their study, Cale \& Lussier (2011) reported that sexually aggressive women are characterized as having experienced early and late-onset antisocial trajectories. More specifically, their study focused on different levels of mating efforts of early and late onset offenders and the established link between mating efforts and sexual offending during adulthood. The results of their study revealed that early onset offenders displayed higher levels of mating effort and sexual drive. Moreover, the two variables: mating efforts and sexual offending, were also strongly associated with an earlier onset and a higher frequency of sexual crimes committed in adulthood. Stated differently, some antisocial trajectories can later influence the sexual lifestyles of those with these early negative experiences that may persist over the life-course. Because of this, scholars report that when studying sex offenders, success was found by focusing on an offenders' entire life experiences since it revealed critical periods and events that chronicled important processes of their violent and nonviolent development. Some of which, were critical turning points for future offenders (Chesney-Lind \& Sheldon, 2004). 


\section{Female Sexual Offending: A Public Health Issue}

Female sexual offending is a public health issue because of its impact on the victims and others living in a community. When viewed as a health issue, public health and governmental agencies are responsible for assuring the safety and well-being of the community by promoting physical health and efficient organization. As such, public health efforts focus on developing strategies that will allow community residents to maintain health (Gostin, 2000). Schneider (2017) reports that health departments are responsible for collecting health statistics, conducting communicable disease control programs, providing screening and immunizations, providing health education services and chronic disease control programs, delivering child health services and providing mental health services.

Public health officials point to the benefits of a sound public health infrastructure (Schneider, 2017). First, it allows for early detection of environmental, behavioral, and other health threats. Second, it allows for concentrated resources and focus interventions in needed areas. Third, it promotes behavioral, social, and environmental changes by identifying and disseminating health information to community residents who are at risk. Gostin (2000) argues that without health care data, it would be impossible for health agencies to identify health risks, inform the public, and influence funding. Consequently, public health approaches rely on epidemiology and biostatistics as its analytical methods and objectives (Gostin, 2000). Together, they provide empirical evidence used in public health to justify public policies that address issues that a community may face including female sexual offending. Health experts contend that epidemiology is an essential part of the public health approach since it is concerned with how, when, and where patterns of disease occur. Its efforts are directed at understanding risk, injury, and diseases within populations. To that end, they examine the frequencies and distributions of disease in the population and use knowledge to control and prevent disease (Gostin, 2000; Schneider, 2017).

While epidemiology was developed to discover and understand the causes of contagious diseases (e.g., smallpox, sexually transmitted infections (STIs), polio, and typhoid), public health experts also use the approach to study factors associated with assaultive violence (e.g., child sexual abuse perpetrated by FSOs). Therefore, when studying victims of FSOs, epidemiologists view the behavior as a disease that can affect many people in a given community (Schneider, 2017). For example, they examine the number of female sexual abuse cases, which is conservatively estimated to be between $12 \%$ and $14 \%$ of sexual abuse cases reported among boys and between 5\% and 6\% of cases reported among girls. However, because of the private nature of child sexual abuse, public health experts are aware that it is highly underreported. Nevertheless, they treat the behavior as an epidemic in the community and throughout society. In doing so, epidemiologists at the $C D C$ and other public health officials use the public health approach to study female sexual offending. Moreover, they view this crime as a public health issue because of the physical and psychological consequences that spill into the healthcare system as a result of assaultive violence.

Public health experts argue justice practitioners (e.g., police, court officials, and correctional personnel) are not medically or clinically trained or equipped to engage in primary prevention of female sexual offending or to even address the aftermath of sexual injuries that typically include victims and offenders experiencing: behavioral issues; depression; anxiety; suicidal thoughts; post-traumatic stress disorder (PTD); sexual health problems (unhealthy sexual relationships); alcohol abuse; drug abuse; and risky sexual practices; sexual violence; and the perpetuation of predatory sexual behavior (Rosenberg \& Fenley, 1991).

\subsection{Implementing Public Health Approaches}

Epidemiologists and public health officials believe that female sex offending preventions must come from intervention quickly after the problem has been identified, either through an assessment by a health agency, or from community concerns reported to authorities after the sexual assault has been discovered (Schneider, 2017. Moreover, Krug and colleagues (2002) argue that public health interventions are divided into three levels of prevention: (1) primary prevention, (2) secondary prevention, and (3) tertiary prevention.

(1). Primary prevention strategies are used to prevent violence before it occurs. They seek to avoid the occurrence of an illness or injury by preventing exposure to risk factors.

(2). Secondary prevention strategies focus on immediate responses to violence, such as getting victims the help they need after victimization (e.g., emergency services, hospitalization, and post-rape STI treatment). They seek to reduce the severity of illnesses or injuries after they occur.

(3). Tertiary prevention strategies are designed to address the long-term health care needs (both physical and psychological) of victims. They focus on rehabilitation and reintegration after victimization. They seek to reduce disability that could be caused by the illness or injury. They also address the crisis aspects of victimization (Krug et al., 2002, p. 15).

Health officials believe this three-pronged prevention approach covers the full range of prevention since these strategies 
are directed at victims, perpetrators, social service providers, and others who respond to violence. The public health approach toward preventing FSOs include educational campaigns to make caregivers and the general public aware of the prevalence of the problem, its causes, its warning signs, and the issues faced by its victims and perpetrators. Public health officials believe that prevention can be achieved by breaking the chain of causation at any link (Schneider, 2017). The public health approach to preventing assaultive violence or female sex offending is composed of five steps: (1) define the health problem, (2) identify the risk factors associated with the problem, (3) develop and test community-level interventions to control and prevent the cause of the problem, (4) implement interventions to improve the health of the population, and (5) monitor those interventions to assess their effectiveness (Krug et al., 2002).

\subsection{Define the Health Problem}

When defining a disease or a crime, epidemiologists use the term disease in a broad sense to mean "health outcome." As such, they contend that efforts must be made to measure the extent of the problem. To accomplish this, these officials examine and analyze data on the number of violence-related behaviors, injuries, and premature deaths (sometimes owing to suicides). Officials believe that these data will reveal the frequency with which violence occurs, where it is likely to occur, and the trends and patterns associated with violence. Experts contend they must also consider the size of the population under study. This helps epidemiologists calculate the rate of violent incidents. Moreover, these data reveal victims, perpetrators, and whether a relationship exists between them. These data are often collected from police reports, emergency room files, vital statistics, medical examiners, registries, population-based surveys (such as the NCVS) and social services.

\subsection{Identify Risk Factors Associated with the Problem}

Public health officials believe that one must also be able to identify factors that both expose and protect people or put them at risk of violence. With regards to female sexual offending, in order to successfully prevent violence, health officials must be able to pinpoint risk factors that increase the likelihood that violence will occur. They must be aware of those factors that will reduce or minimize exposure to such risks. This information informs health officials about where violence can be found so that prevention efforts can be made in crucial areas. To identify risk and protection factors, officials should monitor violence-related injuries. Research shows that risk factors typically include exposure to family violence and alcohol and substance abuse (Gostin, 2000; Schneider, 2017).

\subsection{Develop and Test Community-Level Interventions to Control or Prevent the Cause of the Problem}

Health care officials advocate the need for more research data from needs-assessment tools, community surveys, focus groups, and others involved in violence prevention. They rely on a multidisciplinary effort that includes gathering data from teams made up of officials from social services; justice agencies; mental health agencies; civil justice agencies; health services; policy makers; substance-abuse experts; academics; and others. It is believed that this multidisciplinary approach will allow for a comprehensive assessment of and consultation with health care professionals concerning female sex offending. Furthermore, experts argue that this approach will bridge the gap between multiple agencies and allow for more strategies for addressing female sexual abuse (Gostin, 2000; Schneider, 2017). These data will enable health experts and others to create evidence-based prevention approaches to improve the health of the community.

\subsection{Implement Interventions to Improve the Health of the Population}

After initiating step three and programs have been determined to be successful, health care officials should advocate widespread implementation of effective programs that target female sex offending. This involves making sure that all services that the community needs are available. These include environmental services, educational services, and basic medical services. Because needs often vary, it takes the resources of the entire community to ensure that people get the help they need. Officials should assist in helping state and local participants plan, implement, and evaluate the programs. Moreover, selection and implementation of prevention programs should be followed by evaluation and assessment.

\subsection{Monitor Interventions to Assess their Effectiveness}

After completing step four, health officials should monitor programs to determine if they are successful at preventing female sex offending. The process requires that local health agencies get community representatives involved in evaluating and assessing interventions. During this process, health officials should be concerned with whether there is a decline in the number of sex abuse cases. In the end, the success of the public health approach will inform and help craft future policies related to female sexual offending.

When applying the public health approach to female sexual offending, primary prevention can be used to target all offender typologies by educating everyone regarding the dangers of this victimization as well as the need to protect children and adolescents from other forms of sex abuse. This strategy is concerned with prevention before the behavior occurs. Health experts contend that primary prevention should target teachers and educational setting, with special attention given to school curricula, interpersonal skill training for boys and girls. Children should be encouraged to report 
inappropriate touching and feel safe when reporting behavior they were told to keep secret by someone who could be abusing them. Primary efforts also include targeting communities with massive educational campaigns (via billboards, radio announcements, public service announcement on television and other avenues) about FSO's and the pervasiveness of early sexual abuse, and the need to change the law to hold FSOs more criminally responsible. Moreover, mothers, educators, and others should be provided information about properly caring for children so that their experiences will not be stressful since child experts warn that stressors may cause some women to commit sexual abuse against children. Primary intervention reduces risk factors to which children and adolescents are exposed.

Secondary prevention is achieved by providing sexually abused children and adolescents with therapeutic treatment at rehabilitation centers. Health experts recommend three types of therapy: family, group, and individual. However, the type of therapy and program is contingent on the age of the victim and severity of the sexual abuse experienced. Despite this, the most commonly used sexual abuse therapies include interpersonal therapy (IPT); cognitive-behavioral therapy (CBT); dialectic behavior therapy (DBT); and intensive family therapy (IFT). First, IPT is used to repair damaged relationships by assisting victims with developing healthy ones via social networks and strengthening bonds with loved ones. Second, CBT helps victims replace negative thoughts (such as guilt, shame, or self-blame) related to their sexual abuse experience. Third, DBT is given to survivors who have difficulty accepting past events and realizing they can change their lives in a positive way. Fourth, IFT facilitates health and strong relationships with one's personal support network. In this way, children, adolescence, and even adult survivors of sexual abuse, including female sexual offenders will have resources to help with their victimization. This prevention strategy is essential in minimizing the severity of violent episodes since abusers tend to escalate their violence.

Tertiary prevention is used to stop repeated and continued sexual victimizations. As such, it provides sexual offenders and victims with the therapy and or mental health treatment needed to ensure that sex offending is not repeated or started. To accomplish this, tertiary prevention efforts implement strategies to decrease the likelihood that child sex offending will reoccur. As such, abused families are placed in contact with community professionals who provide the resources needed to address the issue of sex abuse. These programs attempt to rehabilitate and treat sex offenders and victims through intensive treatment and therapy. This area of prevention is critically important to victims since whether assaulted or denied treatment or medications, he or she may experience debilitating injuries that may worsen their condition or contribute to the continuation of the behavior. Because tertiary prevention is focused on prevention, the use of foster care, kinship care, and the sex registry are viewed as such efforts.

\section{Policy Implications}

This investigation disproportionately relied on small samples due in part to the number of FSOs in the population and because many have not been caught or convicted. Despite this, studies and official reports suggest that FSO is on the rise. Therefore, further research should be conducted on this special offending population (McLeod \& Craft, 2015; Stemple et al., 2017). Based upon our findings, we recommend that efforts be made to produce gender parity in understanding the etiology, punishment, treatment, and public health issues related to FSO. As such, our policy recommendations are six-fold. First, there is an increased need to know more about reported and unreported FSO cases. Researchers, justice policymakers, and public health officials should monitor indicators of sexual offenses by females to better understand the factors influencing patterns in the data, why offenses occur, the health disparities caused, as well as the policies and practices designed to treat and prevent sex offending. Second, agencies involved in making policies regarding FSOs should engage in a multidisciplinary collaboration which allows agencies to form partnerships and develop policies aimed at managing and controlling FSOs, assess the victim impact of those policies, and seek input from each partner regarding the most effective manner(s) to hold each FSO accountable while providing support and safety for victims. Similarly, Gostin (2000) contends this combined effort uses multiple strategies that addresses all aspects of female sex abuse. Third, Embry \& Lyons (2012) revealed male sex offenders received sentences between $6 \%$ and $31 \%$ longer than their female counterparts. While studies indicate gender disparity between female and male sex offenders due to FSOs receiving lighter sentences (i.e., the female has traditionally been viewed as a nurturer, not a sex offender), just as the justice system is able to punish male sex offenders, it should equally mete out punishment to FSOs. Justice policies should provide equal sentencing to all sex offenders despite their heterogeneity, especially if the policies are designed to enhance public safety and not give a false sense of security. Fourth, Vess (2011), asserts gender-specific assessments should be conducted to discover factors that contribute to FSO. Justice policymakers and public health practitioners must recognize that FSOs exist and must be given proper gender and case specific treatment in correctional settings. Researchers and scholars must continue to engage the issues of FSO at conferences and in discussions with colleagues. Given the large, and at times, disproportionate representation of women of color in American prisons, additional research should be conducted regarding issues of race and socioeconomic context of FSOs. Fifth, as a matter of public policy and public health, law enforcement personnel, victim advocates, and public health practitioners should further educate communities by providing information on how to protect themselves and their 
families from being victims of FSOs. This information will help individuals recognize the importance and need to manage sex offenders in the community; to realize that there may be more FSOs living in the community who have not been caught; and to identify and verbalize their fears/perceptions about FSOs. The failure to take such action could mean that those who are sexually abused as children and never receive treatment may continue the cycle of violence by abusing others. The general public is often influenced by misinformation regarding sex offenders which leads it to believe that males are the only gender capable of committing sex crimes (Beirne \& Messerschmidt, 2011). Therefore, a paradigm shift is needed whereby policy is driven by empirical data, rather than popular misconception. This will only occur when justice officials and public health practitioners present factual empirical data on FSOs when educating the public about these silent offenders. Sixth, justice personnel are not equipped to engage in the preventative aspects or sexual injuries found among FSOs and their victim(s). Therefore, policies should be developed whereby public health practitioners, who are trained to handle issues specific to FSOs and their victim(s), are employed in cities and in correctional settings. While FSOs have been neglected by the justice system, public health practitioners, and researchers, there is no denying that some advances in knowledge of developmental risk factors have been made. However, more empirical research is needed to explain female sexual offending.

\section{References}

Applewhite, M. (2005). Typologies of adult and adolescent female sexual offenders. A program and service of the national catholic risk retention group, Inc. Retrieved from https//www.virtueonlone.org/virtus/free-articlecfm?Free-articles-id-881

Barnes, J. E., Noll, J. G., Putnam, F. W., \& Trickett, P. K. (2009). Sexual and physical revictimization among victims of severe childhood sexual abuse. Child Abuse Neglect, 33(7), 412-420. https://doi.org/10.1016/j.chiabu.2008.09.013

Bartels, R. M., \& Gannon, T. A. (2011) Understanding the sexual fantasies of sex offenders and their correlates. Aggression and Violent Behavior, 16(6), 551-561. https://doi.org/10.1016/j.avb.2011.08.002

Beirne, P., \& Messerschmidt, J. W. (2011). Criminology: A sociological approach (5th ed.). New York, NY: Oxford University Press.

Benson, M. L. (2002). Crime and the life course: An introduction. Los Angeles, CA: Roxbury Publishing.

Boroughs, D. (2004). Female sexual abusers of children. Child. Youth Serv. Rev, 26, 481-487. https://doi.org/10.1016/j.childyouth.2004.02.007

Bourke, A., Doherty, S., McBride, O., Morgan, K., \& McGee, H. (2014). Female perpetrators of child sexual abuse: Characteristics of the offender and victim. Psychology, Crime \& Law, 20, 769-780. https://doi.org/10.1080/1068316X.2013.860456

Bumby, K. M., \& Bumby, N. H. (1997). Adolescent female sexual offenders. In B. K. Schwartz \& H. R. Cellini (Eds.), The sex offender (pp. 10-1-10-16). Kingston, NJ: CRI.

Bunting, L. (2006). Females who sexually offend against children: Responses of the child protection and criminal justice systems. London, England: National Society for the Prevention of Cruelty to Children.

Burgess-Proctor, Comartin, E. B. A., \& Kubiak, S. P. (2017). Comparing female and male-perpetrated child sexual abuse: A mixed methods approach. Journal of Child Sexual Abuse, 26(6), 657-676. https://doi.org/10.1080/10538712.2017.1336504

Cale, J., \& Lussier, P. (2011). Towards a developmental taxonomy of adult sexual aggressors of women: Antisocial trajectories in youth, mating effort, and sexual criminal activity in adulthood. Violence and Victims, 26(1), 16-32. https://doi.org/10.1891/0886-6708.26.1.16

Chesney-Lind, M. (1995). Girls, delinquency, and juvenile justice: Towards a feminist theory of young women's crime (Pp. 71-88). In The criminal justice system and Women: offenders, victims, and workers, edited by Barbara Raffel Price \& Natalie J. Sokoloff. New York: McGraw-Hill.

Chesney-Lind, M., \& Shelden, R., G. (2004). Girls, delinquency, and juvenile justice (3rd ed.). Belmont, CA: Wadsworth/Thomson.

Cohu, M. (2017). Parenting children or youth who are sexually reactive. Retrieved from https://www.nacac.org/resource/parenting-children-or-youth-who-are-sexually-reactive/

Comartin, E. B., Burgess-Proctor, A., Kubiak, S., Bender, K. A., \& Kernsmith, P. (2018). Comparing women's and men's sexual offending using a statewide incarcerated sample: A two-study design. Journal of Interpersonal Violence, 1-24. https://doi.org/10.1177/0886260518772110

Cortoni, F., Babchishin, K. M., \& Rat, C. (2017). The proportion of sexual offenders who are female is higher than 
thought: A meta-analysis. Criminal Justice and Behavior, 44(2), 145-162. https://doi.org/10.1177/0093854816658923

Cortoni, F., Hanson, R. K., \& Coache, M. (2010). The recidivism rates of female sexual offenders are low: A meta-analysis. Sexual Abuse: A Journal of Research and Treatment, 22, 381-401. https://doi.org/10.1177/1079063210372142

Davies, M., \& Rogers, P. (2006). Perceptions of male victims in depicted sexual assaults: A review of the literature. Aggression and Violent Behavior, 11(4), 367-377. https://doi.org/10.1016/j.avb.2006.01.002

Davin, P., Hislop, J., \& Dunbar, T. (1999). Female sexual abusers: Three views. Brandon, VT: The Safer Society Press.

Elder, G. H. (1985). Perspectives on the life course. In Glen H. Elder, Jr. (ed.). Life course dynamics: Trajectories and transitions, 1968-1980, 23-49. Ithaca, NY: Cornell University Press.

Embry, R., \& Lyons, P. (2012). Sex-based sentencing: Sentencing discrepancies between male and female sex offenders. Feminist Criminology, 7(2), 146-162. https://doi.org/10.1177/1557085111430214

Faller, K. C. (1995). A clinical sample of women who have sexually abuse children. Journal of Child Sexual Abuse, 4(3), 13-29. https://doi.org/10.1300/J070v04n03_02

Finkelhor, D. (2008). Childhood Victimization: Violence, Crime, and Abuse in the Lives of Young People. New York, NY: Oxford University Press. https://doi.org/10.1093/acprof:oso/9780195342857.001.0001

Finkelhor, D., Ormrod, R., \& Chaffin, M. (2009). Juveniles Who Commit Sex Offenses Against Minors. Office of Juvenile Justice and Delinquency Prevention, Washington, DC. https://doi.org/10.1037/e630532009-001

Gannon, T. A., \& Rose, M. R. (2008). Female child sexual offenders: Toward integration and practice. Aggression and Violent Behavior, 13, 442-461. https://doi.org/10.1016/j.avb.2008.07.002

Gostin, L. O. (2000). Public health law: Power, duty, restraint. Berkeley, CA: University of California Press.

Green, A. H. (1999). Female sex offenders. In J. A. Shaw (Ed.), Sexual aggression (pp. 195-210). Washington, DC: American Psychiatric Association Press.

Greenfield, L. (1997). Sex offenses and offenders: An analysis of data on rape and sexual assault. Washington, DC: U.S. Department of Justice, Office of Justice Programs, Bureau of Justice Statistics. https://doi.org/10.1037/e377662004-001

Harris, D. A. (2010). Theories of female sexual offending. In Gannon, T.A., and Cortoni, F. (Eds). Female sexual offenders: theory, assessment, and treatment (pp. 31-52). Hoboken, NJ: Wiley-Blackwell. https://doi.org/10.1002/9780470666715.ch3

Hayes, S., \& Baker, B. (2014). Female sex offenders and parish femininities: Rewriting the sexual scripts. Journal of Criminology, 1-8. https://doi.org/10.1155/2014/414525

Home Office. (2013). An overview of sexual offending in England and Wales: Statistical Bulletin. Ministry of Justice, Home Office and the Office for National Statistics. Retrieved from

https://www.gov.uk/government/uploads/system/uploads/attachment_data/file/214970/sexual-offending-overview-j an-2013.pdf

Hunter, J., \& Mathews, R. (1997). Sexual deviance in females. In Laws \& O' Donohue (Eds.), Sexual deviance: Theory, assessment, and treatment (pp. 465-480). New York: Guilford Press.

Jarrett, C. (2017). Sexual offending by women is surprisingly common, claims US study. Retrieved from https://www.digest.bps.org.uk

Johansson-Love, J., \& Fremouw, W. (2009). Female sex offenders: A controlled comparison of offender and victim/crime characteristics. Journal of Family Violence, 24, 367-376. https://doi.org/10.1007/s10896-009-9236-5

Kaufman, K., Wallace, A., Johnson, C., \& Reeder, M. (1995). Comparing male and female perpetrators modus operandi: Victim's reports of sexual abuse. Journal of Interpersonal Violence, 10(3), 322-333. https://doi.org/10.1177/088626095010003006

Krug, E. G., Dahlberg, L. L., Mercy, J. A., Zwi, A. B., \& Lozano, R. (Eds.). (2002). World report on violence and health. Geneva, Switzerland: World Health Organization. https://doi.org/10.1016/S0140-6736(02)11133-0

Landor, R., \& Eisenchlas, S. (2012). Coming clean on duty of care: Australian print media's representation of male versus female sex offenders in institutional context. Sex. Cult, 16, 486-502. https://doi.org/10.1007/s12119-012-9134-5

Levin, R. J. (2011). Adult manifestations of childhood sexual abuse. The American College of Obstetricians and 
Gynecologists. Committee Opinion.

Lewis, C. F., \& Stanley, C. R. (2000). Women accused of sexual offenses. Behavioral Sciences \& Law, $18,73-81$. https://doi.org/10.1002/(SICI)1099-0798(200001/02)18:1<73::AID-BSL378>3.0.CO;2-\#

Linders, A., \& van Gundy-Yoder, A. (2008). Gall, gallantry, and the gallows: Capital punishment and the social construction of gender, 1840-1920. Gender \& Society, 22(3), 324-348. https://doi.org/10.1177/0891243208318029

Maniglio, R. (2011). The role of childhood trauma, psychological problems, and coping in the development of deviant sexual fantasies in sexual offenders. Clinical Psychology Review, 31(5), 748-756. https://doi.org/10.1016/j.cpr.2011.03.003

Mathews, R., Matthews, J. K., \& Speltz, K. (1989). Female sexual offenders: An exploratory study. Brandon, VT: Safer Society Press.

Matthews, R., Hunter, J. A., \& Vuz, J. (1997). Juvenile female sexual offenders: Clinical characteristics and treatment issues. Sexual Abuse: A Journal of Research and Treatment, 9, 187-199. https://doi.org/10.1177/107906329700900304

McLeod, D. A. (2015). Female offenders in child sexual abuse cases: A national picture. Journal of Child Sexual Abuse, 24(1), 97-114. https://doi.org/10.1080/10538712.2015.978925

McLeod, D. A., \& Craft, M. (2015). Female sexual offenders in child sexual abuse cases: National trends, associated with child protective services system entry, exit, utilization, and socioeconomic. Journal of Public Child Welfare, 9(4), 399-416. https://doi.org/10.1080/15548732.2015.1064849

Messerschmidt, J. W. (1997). Crime as structured action. Gender, race, class, and crime in the making. Newbury Park, CA: Sage Publications. https://doi.org/10.4135/9781452232294

Moffitt, T. E., Caspi, A., Harrington, H., \& Miline, B. J. (2002). Males on the life-course-persistent and adolescence-limited antisocial pathways: Follow-up at age 26 years. Development and Psychopathology, 14(1), 179-207. https://doi.org/10.1017/S0954579402001104

O’Connor, A. A. (1987). Female sex offenders. British Journal of Psychiatry, 150, 615-620. https://doi.org/10.1192/bjp.150.5.615

Ollenburger, J. C., \& Moore, H. A. (1992). A sociology of women: The intersection of patriarchy, capitalism, and colonization. Englewood Cliffs, NJ: Prentice-Hall.

Rosenberg, M. L., \& Fenley, M. A. (1991). Violence in America: A public health approach. New York, Oxford University Press.

Rowntree, M. (2007). Responses to sibling sexual abuse: are they as harmful as the abuse? Australian Social Work 60, 347-361. https://doi.org/10.1080/03124070701519645

Sandler, J. C., \& Freeman, N. J. (2007). Typology of female sex offenders: A test of Vandiver and Kercher Sexual Abuse: A Journal of Research and Treatment, 19, 73-89. https://doi.org/10.1177/107906320701900201

Saradjian, J. (2010). Understanding the prevalence of female-perpetrated sexual abuse and the impact of that abuse on victims. In T. Gannon \& F. Cortoni (Eds.), Female sexual offenders: Theory, assessment, and treatment (pp. 9-30). Malden, MA: Wiley-Blackwell. https://doi.org/10.1002/9780470666715.ch2

Schippers, M. (2007). Recovering the feminine other: Masculinity, femininity, and gender hegemony. Theory and Society, 36(1), 85-102. https://doi.org/10.1007/s11186-007-9022-4

Schneider, M. J. (2017). Introduction to public health (5th ed.). Gaithersburg, MD: An Aspen Publication.

Snyder, H. (2000). Sexual assault of young children as reported to law enforcement: Victim, incident, and offender characteristics. American Bureau of Justice Statistics Clearinghouse. Retrieved December, 2002, from http://www.ojp.usdoj.gov/bjs/312-314

Snyder, H., \& Sickmund, M. (2006). Juvenile offenders and victims: 2006 national report. Washington, DC: U.S. Department of Justice, Office of Justice Programs, Office of Juvenile Justice and Delinquency Prevention.

Solomon, J. C. (1992). Child sexual abuse by family members: A radical feminist perspective. Sex Roles, 27(9/10), 473-485. https://doi.org/10.1007/BF00290004

Stathopoulos, M. (2014). The exception that proves the rule: Female sex offending and the gendered nature of sexual violence. Australian Center for the Study of Sexual Assaults (ACSSA) Research Summary, Australian Institute of Family Studies. 
Stemple, L., Flores, A., \& Meyer, I. H. (2017). Sexual victimization perpetrated by women: Federal data reveal surprising prevalence. Aggression \& Violent Behavior, 33, 302-311. https://doi.org/10.1016/j.avb.2016.09.007

Syed, F., \& Williams, S. (1996). Case studies of female sex offenders in the Correctional Service of Canada. Ottawa, Canada: Correctional Service Canada.

Thornberry, T. (1997). Introduction: Some advantages of developmental and life course perspectives for the study of crime and delinquency. In Terence P. Thornberry (ed.). Developmental Theories of crime and delinquency, pp. 1-10. New Brunswick, NJ: Transaction Publishers.

Tidefors, I., Arvidsson, H., Ingevaldson, S., \&Larsson, M. (2010). Sibling incest: a literature review and a clinical study. Journal of Sexual Aggression, 16, 347-360. https://doi.org/10.1080/13552600903511667

Tozdan, S., Briken, P., \& Dekker, A. (2019). Uncovering female child sexual offenders-needs and challenges for practice and research. Journal of Clinical Medicine, 8(3), 401-411. https://doi.org/10.3390/jcm8030401

Travin, S., Cullen, K., \& Protter, B. (1990). Female sex offenders: Severe victims and victimizers. Journal of Forensic Sciences, 35(1), 140-150. https://doi.org/10.1520/JFS12811J

Vandiver, D., \& Kercher, G. (2004). Offender and victim characteristics of registered female sexual offenders in Texas: A proposed typology of female sexual offenders. Sexual Abuse: A Journal of Research and Treatment, 16, 121-137. https://doi.org/10.1177/107906320401600203

Vess, J. (2011). Risk assessment with female sex offenders: Can women meet the criteria of community protection laws? Journal of Sexual Aggression, 17(1), 34-45. https://doi.org/10.1080/13552600.2010.528844

West, C., \& Zimmerman, D. H. (1987). Doing gender. Gender \& Society, 1(2), 125-151. https://doi.org/10.1177/0891243287001002002

White, R., \& Haines, F. (2008). Crime and criminology. Oxford: Oxford University Press.

Wijkman, M., Bijleveld, C., \& Hendriks, J. (2010). Women don't do such things! characteristics of female sex offenders and offender types. Sexual Abuse, 22(2), 135-156. https://doi.org/10.1177/1079063210363826

William, K. S., \& Bierie, D. M. (2014). An-incident-based comparison of female and male sexual offenders. Sexual Abuse, 27(3), 235-57. https://doi.org/10.1177/1079063214544333

Wiseman, J. (2015). Incidence and prevalence of sexual offending (Part I). SOMAPI Research Brief. Office of Justice Programs, U.S. Department of Justice.

Zack, E., Lang, J. T., \& Dirks, D. (2018). “It must be great being a female pedophile!”: The nature of publicperceptions about female teacher sex offenders. Crime Media Culture, 14(1), 61-79.

https://doi.org/10.1177/1741659016674044

\section{Copyrights}

Copyright for this article is retained by the author(s), with first publication rights granted to the journal.

This is an open-access article distributed under the terms and conditions of the Creative Commons Attribution license which permits unrestricted use, distribution, and reproduction in any medium, provided the original work is properly cited. 